\title{
Experimental study of combustion characteristics of the airplane aviation carpet
}

\author{
Chao Feng ${ }^{1, a}$, Jian Chen ${ }^{2, b}$ and Wenlong Deng ${ }^{3, c}$ \\ ${ }^{1}$ Shenyang Aerospace University, Liaoning province of China \\ ${ }^{2}$ Shenyang Aerospace University, Liaoning province of China \\ ${ }^{3}$ Shenyang Aerospace University, Liaoning province of China \\ a770343510@qq.com, b656569756@qq.com, ${ }^{\mathrm{c}} 1547069412 @ q q . c o m$
}

Keywords: combustion characteristics, airplane aviation carpet

Abstract: The experiments show that aviation wool carpet will not fire spread, composite airworthiness standards in the carpet surface, but it can be inferred from the fitting equation when the temperature continues to rise, causing the surface of the carpet is very huge possibility of the spread of fire. In addition, the aircraft event of fire, fire temperatures up to about $1000^{\circ}$, so the carpet is prone to fire spread, resulting in the development of fire spread, causing a fire in this life. This point should be emphasized.

\section{Introduction}

Aircraft carpet is an important part of interior decoration, in course of the fire, the carpet not only provides a large fire load but also conducive to the spread of fire in the horizontal direction, while greatly increasing the release of toxic fumes, so that increase fire hazards, combustion performance is an important factor in fire occurrence and development [1]. About carpet combustion performance has been more research [2-4]. Currently interior mainly uses synthetic carpets and wool carpets, they belong to two raw materials are flammable materials.

Correct evaluation of aviation carpet fire occurred in the interior and the development of the role of great significance. In this paper cone calorimeter combustion performance of several carpets on the market was studied experimentally.

\section{Experimental}

In this paper cone calorimeter at different radiation intensities experimental research on synthetic carpets and a wool carpet on combustion performance of aircraft used. Thermal radiation strength tests were used $35 \mathrm{kw} / \mathrm{m} 2,45 \mathrm{kw} / \mathrm{m} 2$ and $50 \mathrm{kw} / \mathrm{m} 2$, according to ISO5660 standard test procedure [5], in the same heat radiation intensity, three parallel experiments each sample were then averaged Compare. Civil aviation wool carpets wool carpets and origin of Shenyang and Beijing. The actual thickness of the sample thickness, respectively $5 \mathrm{~mm}$.

\section{Results and discussion}

\section{ignition time (TTI)}

Ignition time is the sample from the heat radiation to the surface of the light-emitting time between flame. Ignition time reflects the difficulty of the material is ignited and the combustion characteristics of the material are to evaluate one of the important parameters. Under the same 
conditions the shorter the ignition time of the material, the more easily ignited explanatory material, the greater its fire danger.

Table 1 lists the civil aviation wool carpets wool carpets and thermal radiation intensity at different ignition time. Data listed in the table can be seen. The civilian pilot wool carpet wool carpet time was less than aviation that described civil aviation wool carpet wool carpet representing more easily ignite. Both the carpet ignition time with increasing radiation heat intensity decreases.

Table 1 two kinds of carpet ignition time

\begin{tabular}{|l|c|c|c|}
\hline \multirow{2}{*}{ Aviation carpet } & \multicolumn{3}{|c|}{ ignition time $(\mathrm{s})$} \\
\cline { 2 - 4 } & $35\left(\mathrm{kw} / \mathrm{m}^{2}\right)$ & $45\left(\mathrm{kw} / \mathrm{m}^{2}\right)$ & $50\left(\mathrm{kw} / \mathrm{m}^{2}\right)$ \\
\hline Civil wool carpets & 86 & 46 & 30 \\
\hline Aviation wool carpet & 138 & 74 & 67 \\
\hline
\end{tabular}

\section{heat release rate $($ HRR)}

Heat release rate is the unit time per unit area of material burning rate of heat release. Heat release rate is one of the evaluate the size of combustion behavior of materials important parameters and peak heat release rate is to evaluate the material fire safety performance of the most important indicators [7]. Generally speaking, in the small scale fire tests, the high rate of heat release in lighting time is short and fast burning speed of material fire danger.

Carpet combustion can be divided into two stages, namely primary combustion stage burning carpet and carpet material itself. Carpet grass decompose first deposited on the surface of a flammable gas, and then the release of flammable gas exploded carpet material. This stage if the temperature is high, it will cause burning the fire spread quickly. In the early days when the flame burning, mainly caused by the burning carpet grass-roots, seen from the figure is the first peak, burning carpet material is not only the second peak. This stage high temperature, long time and rapid fire development.

Figure 1-2 respectively the radiation intensity at $35 \mathrm{kw} / \mathrm{m} 2,45 \mathrm{kw} / \mathrm{m} 2$ and $50 \mathrm{kw} / \mathrm{m} 2$ under civil wool carpets and heat release rate curve aviation wool carpets. From Figures 1 to 2 can be seen in the heat release rate at different radiation intensities of two carpets have appeared two peaks. After ignition, flammable pyrolysis products fast first forming a steeper peak combustion, as burning carpet material, so that the heat release rate is reduced. With the decrease of the pyrolysis rate, so that heat released by combustion carpet accelerated, resulting in a second peak.

Heat release rate curve civil aviation wool carpets and wool carpets are very similar, and wool carpets heat release rate was significantly ahead of the first peak. Table 2 lists the two carpet average heat release rate and the first peak heat release rate within 300 s before the heat radiation at different intensities.

Figures 3 and 4 respectively the heat release rate curves under different radiation power of civilian and civilian wool carpets wool carpets can be seen. The heat release rate increases with increasing radiation intensity and the peak with increasing radiation intensity is significantly ahead of schedule.

Figures 1 and 2 are in the heat release rate of three radiation intensity carpet curve. The first peak after a steep ignite flammable due to the rapid combustion of the pyrolysis products are formed, with the intensification of the carpet so that the heat release rate of decomposition of the second peak occurs. If the carpet backing retardant effect, it will delay the arrival time of the first peak, the heat release rate will be in a stable state. 
Table 2 HRR

\begin{tabular}{|c|c|c|c|}
\hline \multirow{2}{*}{ Radiation intensity } & \multicolumn{3}{|c|}{ HRR $(300 \mathrm{~s})$} \\
\cline { 2 - 4 } & $35\left(\mathrm{~kW} / \mathrm{m}^{2}\right)$ & $45\left(\mathrm{~kW} / \mathrm{m}^{2}\right)$ & $50\left(\mathrm{~kW} / \mathrm{m}^{2}\right)$ \\
\hline Civil wool carpets & 46.7 & 59.2 & 66.5 \\
\hline Aviation wool carpet & 37.8 & 51.9 & 64.87 \\
\hline
\end{tabular}

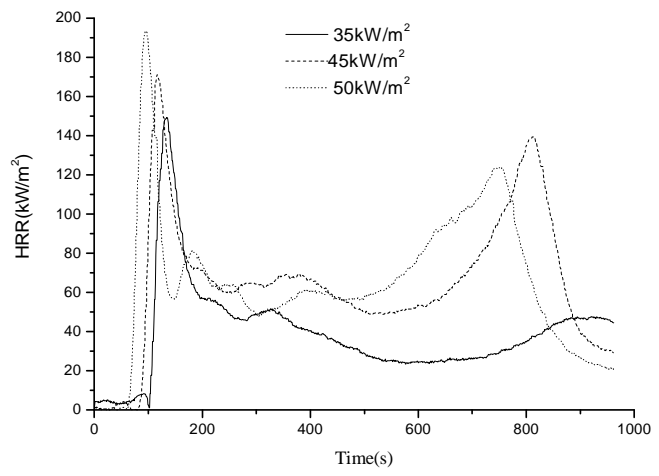

Figure 1

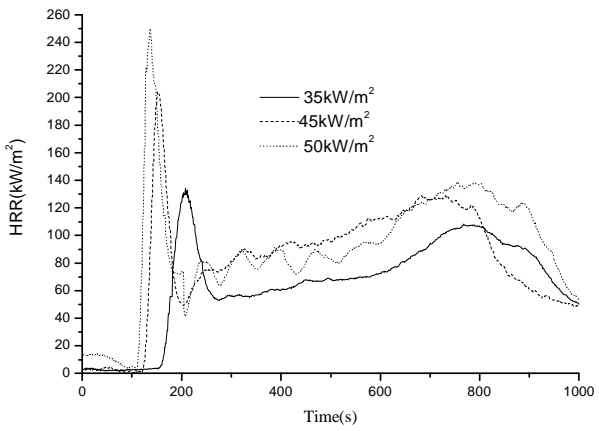

Figure 2

\section{The total heat release (THR)}

Cone Calorimeter experiment test sample is the sum of the total heat release per unit area of the specimen after complete combustion heat release, in units of MJ / $\mathrm{m} 2$. The total heat release is to evaluate the actual use of thermal hazards important parameters. The larger the total heat release material, the greater the risk materials potentially hot. As can be seen from the test data set, the total heat release aviation wool carpets wool carpets than the total heat release of civilian small, mainly due to aviation wool rug add a certain amount of flame retardant to slow the rate of decomposition, so the unit time Decomposition combustibles within significantly less than the number of civilian carpets, wool carpets and civilian under high temperature grading swift and released per unit time fuel in larger quantities, so large heat release.

Table 3 the aviation carpet and general carpet maximum heat release rate

\begin{tabular}{c|c|c}
\hline Radiation intensity $\left(\mathrm{kw} / \mathrm{m}^{2}\right)$ & $\begin{array}{l}\text { the aviation carpet maximum } \\
\text { heat release rate }\end{array}$ & $\begin{array}{l}\text { the general carpet maximum } \\
\text { heat release rate }\end{array}$ \\
\hline 35 & 141.4 & 387.7 \\
\hline 45 & 138.9 & 400.7 \\
\hline 50 & 140.6 & 416.3 \\
\hline
\end{tabular}

\section{flue gas composition and content}

Two kinds of samples in the thermal radiation intensity of $45 \mathrm{~kW} / \mathrm{m} 2$ and $50 \mathrm{~kW} / \mathrm{m} 2 \mathrm{ppm}$ concentration of carbon monoxide in the flue gas with time curve (600s within). Under radiation intensity $45 \mathrm{~kW} / \mathrm{m} 2$ and $50 \mathrm{~kW} / \mathrm{m} 2$ of aviation carpet burn more quickly and CO concentration released soon reach the peak. The concentration of $\mathrm{CO}$ generated also has two peaks as the heat release rate. In the latter part of the experiment, aviation carpet from flaming into a flameless combustion, the concentration of $\mathrm{CO}$ straight rise. The average $\mathrm{CO}$ concentration ordinary carpet produced for 0.057735312 , compared to ordinary carpet, a small concentration of aviation carpet CO combustion processes of many, this shows that the two materials are considered separately, then 
the concentration of $\mathrm{CO}$ combustion, aviation carpet the toxicity of a relatively small box. Heat release rate of ordinary carpet is relatively large, but the concentration of $\mathrm{CO}$ is relatively large, it may be because regular carpet burn faster, heat release rate is relatively large, ordinary carpet material at this temperature reached ignition point, but the unit time The amount of oxygen is constant, thus resulting in regular carpet in some of the substances not fully burn, produce large amounts of $\mathrm{CO}$.

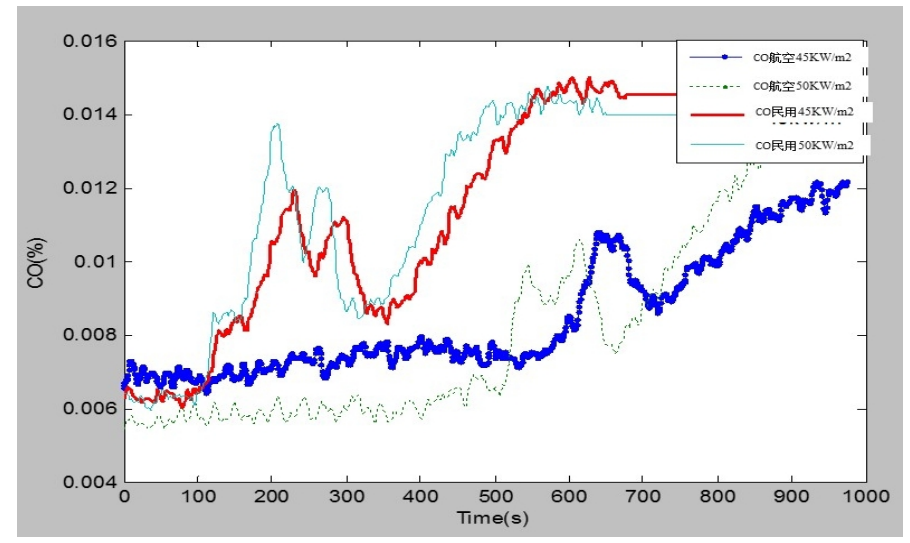

Figure 3 Two carpet combustion $\mathrm{CO}$ concentration changes

\section{Aviation carpet fire spread length}

Table 4 Aviation carpet material conditions under $20{ }^{\circ} \mathrm{C} 、 60{ }^{\circ} \mathrm{C} 、 90^{\circ} \mathrm{C} 、 140^{\circ} \mathrm{C}$ combustion conditions and the spread of fire.

Table 4 Aviation carpet under the different temperature of experimental phenomena

\begin{tabular}{|c|c|c|c|c|}
\hline Material number & $\begin{array}{c}\text { Temperature } \\
\left({ }^{0} \mathrm{C}\right)\end{array}$ & $\begin{array}{l}\text { char } \\
\text { length }\end{array}$ & $\begin{array}{c}\text { width } \\
\text { charred }(\mathrm{cm})\end{array}$ & experimental phenomena \\
\hline Aviation carpet 1 & 20 & 11.5 & 5.6 & charred carpet is not obvious \\
\hline Aviation carpet 2 & 60 & 14.5 & 7.8 & $\begin{array}{c}\text { carpet sample a little bit rolled } \\
\text { up, charred clear }\end{array}$ \\
\hline Aviation carpet 3 & 90 & 15 & 8.8 & $\begin{array}{c}\text { Sample rolled serious, serious } \\
\text { burning, carbonization }\end{array}$ \\
\hline Aviation carpet 4 & 140 & 18 & 10.5 & $\begin{array}{l}\text { specimen fracture, charred } \\
\text { serious, serious carbonation }\end{array}$ \\
\hline
\end{tabular}

From the graph and the equation, it can clearly show that at a certain temperature, although aviation carpet at the set temperature, without burning fire spread, the increase of temperature, the experiment charred the length and width is charred on the increase, and at a certain temperature increased linearly. That is the length and width of charred higher the temperature the longer the scorch, and the degree of charred more serious, indicating a problem, although aviation carpet at room temperature or at a certain temperature is not burning can also be said to be at a certain temperature is flame retardant, as the temperature rises, one or more of the substance material may be decomposed, this time the decomposition of the substances may occur burn. 


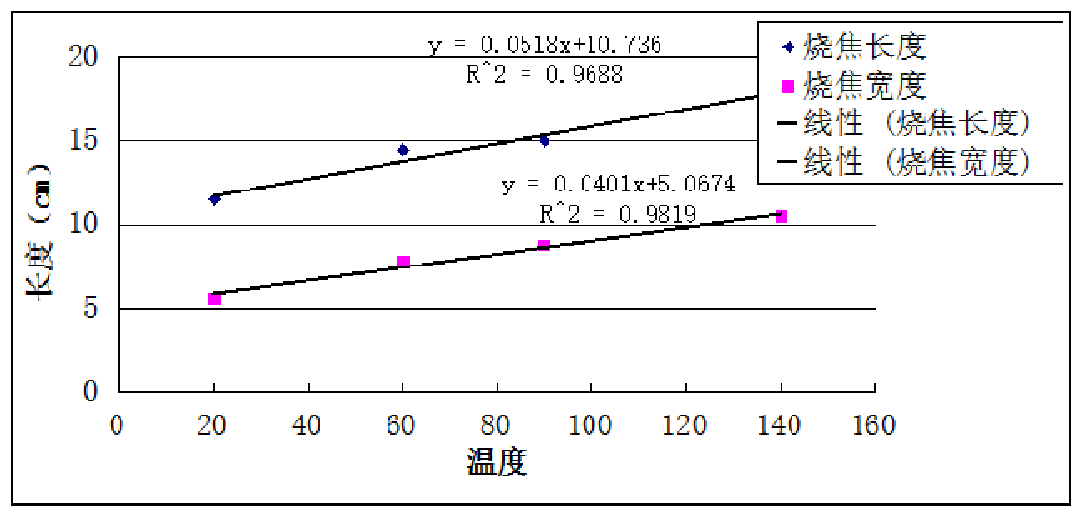

Figure 4 char length and width variation with temperature scorched Figure

\section{conclusions}

From the above analysis of test results the following conclusions can be drawn from the discussion:

(1) Civil wool carpet ignition time is shorter, the critical ignition thermal radiation heat flux is small, compared with the aviation wool carpets, which increases risk of ignition.

(2) Civil wool carpet in the initial combustion heat release rate is larger, the time the first peak heat release rate appears short and its potential flashover risk is high.

(3) Air wool rug total heat release significantly less than the total heat release civilian wool carpets, and therefore its thermal hazards in the early stages of combustion is relatively large.

(4) The experiments show that aviation wool carpet will not fire spread, composite airworthiness standards in the carpet surface, but it can be inferred from the fitting equation when the temperature continues to rise, causing the surface of the carpet is very huge possibility of the spread of fire. In addition, the aircraft event of fire, fire temperatures up to about $1000^{\circ}$, so the carpet is prone to fire spread, resulting in the development of fire spread, causing a fire in this life. This point should be emphasized.

\section{References}

[1] Zhongjun Shu, Qiang Chen. Fire Performances of Bamboo Floor Covering Compared to Wood Floor Covering by Cone Calorimeter Test. Fire Safety Science. 2007 , 16(3) :148-151.

[2] Cui Zhao, Shujie Yuan, Mingxia He. Experimental study on TGA comparison of several typical wooden flooring materials. Journal of Safety Science and Technology. 2013 , 9(6) :37-41.

[3] Cui Zhao, Shujie Yuan, Mingxia He. Experimental study on TGA comparison of several typical wooden flooring materials. Journal of Safety Science and Technology. 2013 , 9(6) :37-41.

[4] Jing Luo, Gang Fan, Yanqiong Zheng, Zhi Li, Fei Cui. Differential Thermal Analysis on Several Kinds of Wooden Floor Materials. China Safety Science Journal. 2012 , 22(1) :65-69.

[5] Minggao $\mathrm{Yu}$, Die Meng, Chang Lu, Hongyan Ma.Experimental study on the burning behavior of straw with different radiant intensities. Fire Safety Science.2010 , 19(4) :212-216. 